\title{
ESTAQUIA DO PORTA-ENXERTO DE VIDEIRA ‘43-43’ (V. vinifera x V. rotundifolia) RESISTENTE À Eurhizococchus brasiliensis ${ }^{1}$
}

\author{
RENATO VASCONCELOS BOTELHO², ALINE JOSÉ MAIA³, ERASMO JOSÉ PAIOLI PIRES4, \\ MAURILO MONTEIRO TERRA ${ }^{3}$, ENIO SCHUCK ${ }^{5}$
}

\begin{abstract}
RESUMO - O experimento foi realizado com o objetivo de avaliar a propagação vegetativa por estaquia do porta-enxerto de videira ‘43-43’ . Ramos herbáceos coletados em janeiro e semilenhosos em março que foram separados em dois lotes: um de estacas retiradas do ápice e outro da base dos ramos. As estacas foram então imersas por 10 segundos em soluções contendo diferentes concentrações de ácido indolilbutírico (0; 1.000; 1.500; 2.000; 2.500 ou $3.000 \mathrm{mg} . \mathrm{L}^{-1}$ ), totalizando 12 tratamentos para cada época de enraizamento. Posteriormente, as estacas foram plantadas em vasos de polipropileno com areia e mantidas em casa de vegetação sob sistema de nebulização. Sessenta dias após o plantio das estacas, para cada época, foram avaliadas as seguintes variáveis: porcentagem de estacas enraizadas, comprimento médio de raízes, massa fresca de raízes e porcentagem de estacas brotadas. Estacas herbáceas e semilenhosas apresentaram alta porcentagem de enraizamento (66,0\% e 68,0\%, respectivamente) mesmo quando não tratadas com o fitorregulador. Estacas apicais apresentaram maior comprimento e massa fresca de raízes. A aplicação de AIB reduziu a porcentagem de enraizamento e de brotação de estacas herbáceas e semilenhosas. Estacas semilenhosas, quando tratadas com o AIB a 1.000 mgL ${ }^{-1}$, apresentaram maior comprimento e massa fresca de raízes.
\end{abstract}

Termos para indexação: uva, ácido indol butírico, enraizamento, propagação vegetativa

\section{CUTTING OF THE VINE ROOTSTOCK '43-43' (V. vinifera x V. rotundifolia) RESISTANT TO Eurhizococchus brasiliensis}

\begin{abstract}
A trial was carried out aiming to evaluate the vegetative propagation by cutting for the vine rootstock '43-43'. Softwood shoots collected in January - and semi-hardwood shoots collected in March - were divided in two lots: one of the cutting was taken from the apex and the other from the base. The cuttings were immersed in solutions, by 10 minutes, containing different doses of indole butyiric acid (0, 1000, 1500, 2000, 2500 or $3000 \mathrm{mgL}^{-1}$ ), totalizing 12 treatments for each epoch of rooting. After that, the cuttings were planted in polypropylene vases with sand and kept under misty system irrigation. Sixty days after planting the cuttings, for each epoch, the following variables were evaluated: percentage of rooted cuttings, length and fresh weight of roots and percentage of sprouted cuttings. The softwood and semi-hardwood cuttings presented high percentage of rooting (66\% and 68\%, respectively) even when not treated with the plant regulator. Apical cuttings presented higher length and fresh weight of roots. The IBA application reduced the percentage of rotting and sprouting of softwood and semi-hardwood cuttings. The semi-hardwood cuttings that were treated with IBA at $1,000 \mathrm{mgL}^{-1}$ showed the highest length and the freshest weight of roots.
\end{abstract}

Index terms: grape, indole butyric acid, rooting, vegetative propagation

\section{INTRODUÇÃo}

Um dos fatores limitantes na viticultura, principalmente na região Sul do Brasil, é a ocorrência de uma cochonilha de hábito subterrâneo denominada pérola-da-terra (Eurhizococchus brasiliensis) que suga a seiva das raízes, provocando um definhamento progressivo da videira (Papa \& Botton, 2001).

Para o controle desta praga, no entanto, o uso de métodos convencionais, como aplicações de inseticidas sistêmicos, consegue no máximo 70\% de eficiência (Papa \& Botton, 2001). Uma das formas de controle que apresenta potencialidade, devido ao seu baixo custo e pequeno risco de desequilíbrio ambiental, é o uso de porta-enxertos resistentes, tais como aqueles derivados da espécie Vitis rotundifolia (Soria et al., 1999).

Contudo, segundo Pires \& Biasi (2003), estacas lenhosas de variedades da seção Muscadínea (Vitis rotundifolia), da família Vitaceae, assim como seus híbridos, apresentam baixo índice de enraizamento, possivelmente devido à presença de inibidores ou ausência de substâncias promotoras, o que torna sua utilização limitada.

A eficácia do enraizamento de estacas varia com a fase de desenvolvimento e idade da planta, com o tipo e a localização da estaca, bem como a época do ano (Janick, 1966). Segundo Kramer \& Kozlowski (1960), o enraizamento das estacas da base dos ramos é normalmente melhor que das estacas do ápice devido a sua maior disponibilidade de carboidratos.

De acordo com Zuffellato-Ribas \& Rodrigues (2001), o enraizamento de estacas é influenciado pela auxina, sendo que, em numerosas plantas, este processo é grandemente aumentado pela aplicação de auxinas sintéticas. O ácido indolilbutírico (AIB) é, provavelmente, o melhor fitorregulador de uso geral, porque não é tóxico para a maioria das plantas mesmo em altas concentrações, é bastante efetivo para um grande número de espécies e relativamente estável, sendo pouco suscetível à ação dos sistemas de enzimas de degradação de auxinas (Pires \& Biasi, 2003).

Reddy et al. (1996) estudaram o efeito de sete concentrações de AIB no enraizamento de 13 diferentes variedades de videira. Os melhores resultados, em termos de porcentagem de enraizamento e comprimento médio das raízes, foram observados para a solução de AIB a 1.250 mg. $\mathrm{L}^{-1}$, enquanto o número de raízes por estacas foi maior com a dose de $2.500 \mathrm{mg} . \mathrm{L}^{-1}$.

Neste contexto, o trabalho teve como objetivo avaliar a propagação vegetativa por estaquia do porta-enxerto '43 - 43' ( Vitis vinifera $X$ Vitis rotundifolia) para tornar a sua utilização viável na viticultura comercial.

\section{MATERIAL E MÉTODOS}

Estacas provenientes de plantas-matrizes do porta-enxerto de videira '43-43' (Vitis vinifera $x$ Vitis rotundifolia) foram obtidas em duas épocas diferentes: estacas herbáceas em janeiro e semilenhosas em março. Estas foram, então, separadas em dois lotes: um lote de estacas provenientes da base até a região mediana dos ramos e outro de estacas

\footnotetext{
(Trabalho 150/2005). Recebido: 13/09/2005. Aceito para publicação: 09/12/2005.

2 Eng. Agr. Dr. Professor Adjunto. Departamento de Agronomia, UNICENTRO. R. Simeão Varela de Sá nº 03, 85040-080 Guarapuava-PR. E-mail: rbotelho@unicentro.br.

${ }^{3}$ Acadêmica do curso de Agronomia, UNICENTRO. Bolsista de Iniciação Cientifica - PIBIC UNICENTRO/CNPq.

${ }^{4}$ Eng. Agr. Dr. Pesquisador Científico. Instituto Agronômico de Campinas. Centro de Ecofisiologia e Biofísica. Caixa Postal 28, 13001-970 Campinas-SP.

${ }^{5}$ Eng. Agr. M.Sc. Pesquisador Centífico. EPAGRI, Estação Experimental de Videira. C.P. 21, 89560-000 Videira-SC.
} 


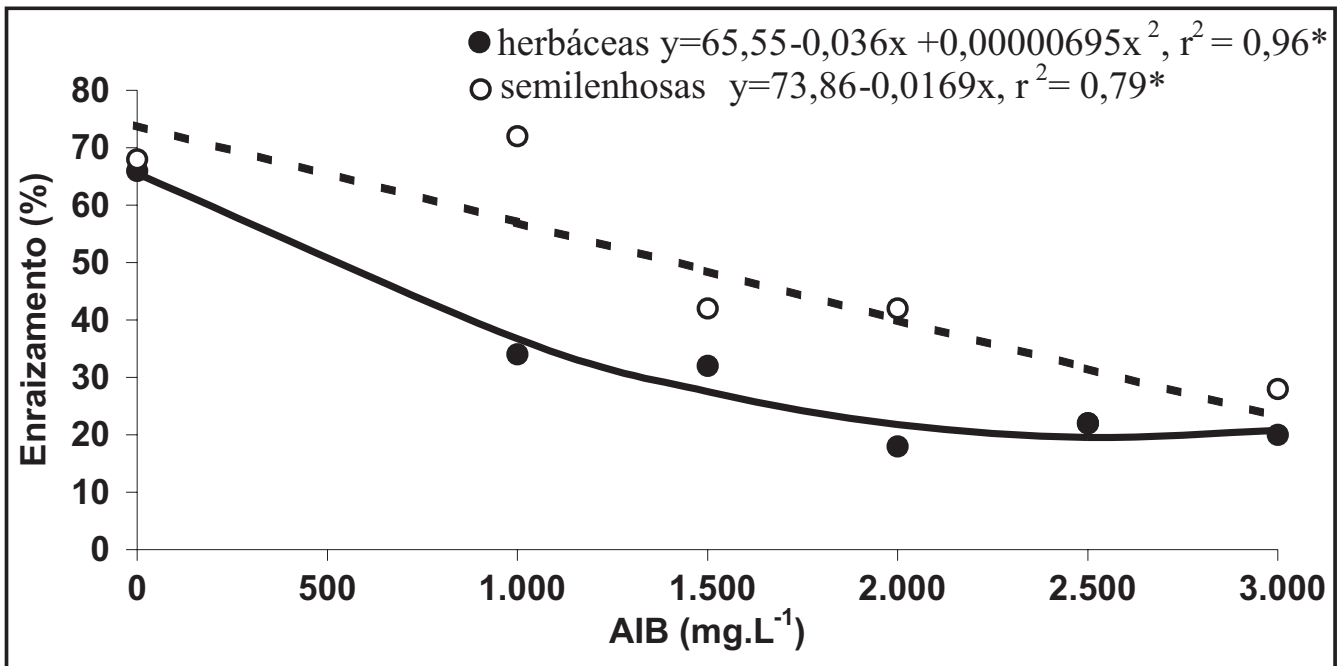

FIGURA 1 - Porcentagem de enraizamento de estacas herbáceas e semilenhosas do porta-enxerto de videira '43-43' tratadas com diferentes doses de AIB.

oriundas a partir da região mediana até o ápice dos ramos.

Posteriormente, as estacas foram preparadas com 2 a 3 gemas cada (cerca de 15 a 20 cm), cortando-se a porção inferior em bizel, em posição oposta a uma gema; e na porção superior reta, acima de uma gema. Cada estaca foi mantida com uma folha tendo sua área reduzida em 30\%. Em seguida, as estacas foram tratadas na sua parte basal com solução de ácido indolilbutírico (AIB) nas concentrações de $0 ; 1.000$; 1.500; 2.000; 2.500 ou 3.000 mg. $\mathrm{L}^{-1}$, por 10 segundos.

Depois do tratamento com o fitorregulador, as estacas foram plantadas em vasos de plástico rígido, medindo 45 x $17 \mathrm{~cm}$ e $14 \mathrm{~cm}$ de altura, contendo areia como substrato, e mantidas em casa de vegetação sob nebulização intermitente.

Nas duas épocas de retirada de estacas, o delineamento experimental adotado foi o inteiramente casualizado, em esquema fatorial $6 \times 2$ (doses de AIB x tipo de estaca), com seis repetições, e cada parcela experimental constituída por um vaso contendo cinco estacas.

Após 60 dias do plantio das estacas, as seguintes variáveis foram avaliadas: porcentagem de estacas enraizadas, comprimento médio de raízes, massa fresca de raízes e porcentagem de estacas com brotações.

Os resultados obtidos foram submetidos à análise de variância, estudando-se a interação entre os fatores.

\section{RESULTADOS}

Para a variável porcentagem de enraizamento, não houve interação entre os fatores em nenhuma das épocas estudadas. Nas estacas herbáceas, verificou-se efeito quadrático para o fator doses de AIB (Figura 1), independentemente da posição de origem da estaca (ápice ou base), sendo que a testemunha apresentou $66 \%$ de estacas enraizadas contra $20 \%$ do tratamento a $3.000 \mathrm{mgL}^{-1}$ de AIB.

Para as estacas semilenhosas, houve efeito linear negativo das doses de AIB (Figura 1), sendo que as estacas da testemunha apresentaram $68 \%$ de enraizamento, enquanto aquelas tratadas com AIB a $3.000 \mathrm{mg} . \mathrm{L}^{-1}$ tiveram apenas $28 \%$.

Para as estacas herbáceas, não foi verificada interação entre os fatores em relação à variável comprimento médio de raízes, mas houve efeito significativo de estacas e doses, isoladamente. Para o fator doses, constatou-se efeito linear negativo, onde a testemunha apresentou maior comprimento médio de raízes $(9,29 \mathrm{~cm})$ (Figura 2A). As estacas apicais tiveram maior comprimento médio de raízes $(10,39 \mathrm{~cm})$ do que as estacas basais $(6,24 \mathrm{~cm})$, independentemente da dose de AIB (Figura 2B).

Para as estacas semilenhosas, verificou-se interação entre os fatores para esta variável. Apenas as estacas basais do ramo apresentaram efeito quadrático para os níveis de doses. A dose estimada

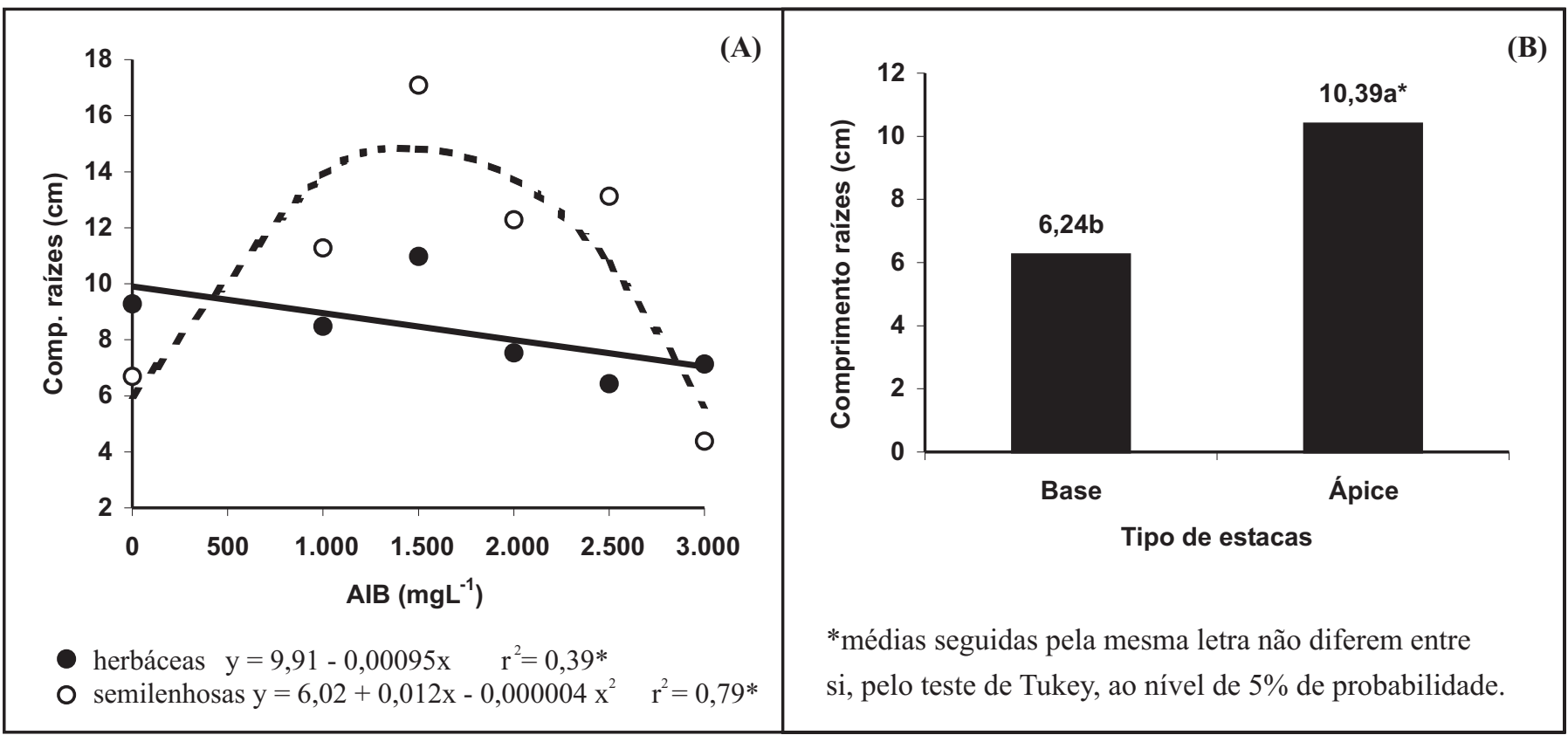

FIGURA 2 - Comprimento de raízes de estacas herbáceas e semilenhosas do porta-enxerto de videira ‘43-43’ tratadas com diferentes doses de AIB (A) e de estacas herbáceas da base e do ápice dos ramos (B). 


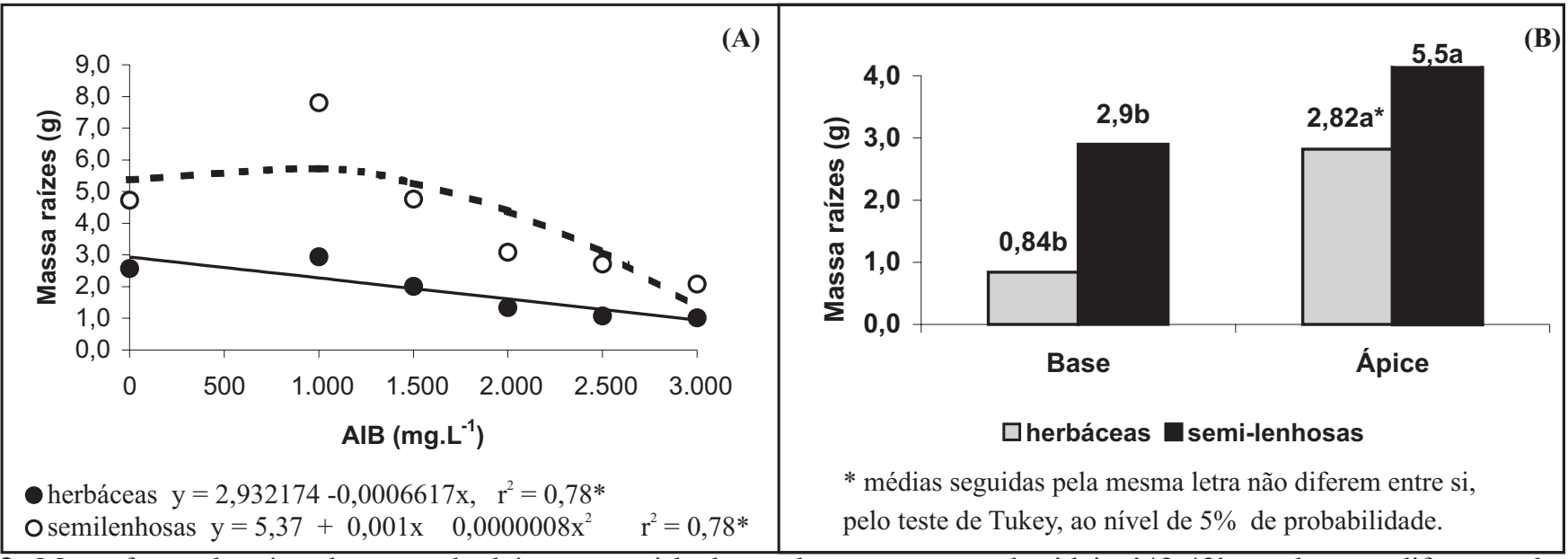

FIGURA 3 - Massa fresca de raízes de estacas herbáceas e semi-lenhosas do porta-enxerto de videira '43-43' tratadas com diferentes doses de AIB (A) e retiradas da base e do ápice do ramo (B) .

para o maior comprimento médio de raízes foi de 1.486,5 mg.L $\mathrm{L}^{-1}$ de AIB, ocorrendo posterior decréscimo com o aumento das doses (Figura 2A).

Em estacas herbáceas, verificaram-se efeitos dos fatores estacas e doses para a variável massa fresca de raízes, não tendo ocorrido interação. $\mathrm{O}$ fator doses teve um efeito linear negativo, onde se observou que, com o aumento das concentrações de AIB, ocorreu um decréscimo da massa fresca de raízes (Figura 3A). Na Figura 3B, observa-se que as estacas do ápice obtiveram a maior massa fresca de raízes $(2,82 \mathrm{~g})$, enquanto as estacas da base apresentaram a menor média $(0,84 g)$.

Em estacas semilenhosas também não houve interação entre os fatores para esta variável, porém ocorreu efeito significativo de estacas e doses, independentemente. Para o fator doses, houve efeito quadrático, onde se observou que a massa fresca de raízes apresentou aumento com as concentrações de AIB até a dose estimada de 702 mg. $L^{-1}$, e posterior decréscimo (Figura 3A). Na Figura 3B, verifica-se que as estacas apicais obtiveram maior massa fresca de raízes (5,5 g), enquanto as estacas da base apresentaram a menor média (2,9 g).

Nas estacas herbáceas, houve efeito quadrático do fator doses para a variável porcentagem de brotação, onde se verificou que a testemunha apresentou a maior porcentagem de brotação (62\%) (Figura 4A).

Em relação às estacas semilenhosas, não houve interação entre os fatores para a variável porcentagem de brotação, porém houve efeitos significativos de estacas e doses, isoladamente. Para o fator doses, ocorreu efeito linear negativo, sendo que as estacas do tratamento-testemunha apresentaram $22 \%$ de brotação, enquanto aquelas tratadas com 3.000mg.L ${ }^{1}$ de AIB apenas 4\% (Figura 4A). Na Figura 4B, observa-se que as estacas da base apresentaram maior porcentagem de brotação (16,67\%) do que as estacas do ápice (9,33\%), independentemente das doses de AIB.

\section{DISCUSSÃO}

De maneira geral, a utilização de AIB foi prejudicial ao enraizamento das estacas herbáceas e semilenhosas do porta-enxerto de videira '43-43' (Figura 5), estando de acordo com os resultados de Bastos (2002), que observou não ser necessário o emprego de fitorregulador de crescimento para o enraizamento de estacas herbáceas de caramboleira. Da mesma forma, Biasi et al. (1997) não observaram aumento significativo no enraizamento de estacas semilenhosas de diferentes porta-enxertos de videiras mediante aplicação de AIB.

Para Fachinello et al. (1995), o sucesso do enraizamento de estacas semilenhosas se deve à presença de tecidos mais tenros, não havendo, conseqüentemente, um anel de esclerênquima altamente lignificado que dificultaria a emissão dos primórdios radiculares.

Para as estacas herbáceas e semilenhosas, aquelas provenientes do ápice do ramo apresentaram os maiores valores de massa e comprimento de raízes. De forma semelhante, Bastos et al. (2004) verificam que as estacas do ápice de caramboleira apresentam maior capacidade de enraizamento em relação às estacas da base. Segundo Ono \& Rodrigues (1996), tal fato pode ser atribuído ao maior grau de lignificação das estacas da base que parece estar correlacionado diretamente à presença de enzimas tais como as peroxidases, que estão envolvidas tanto na síntese de lignina como na degradação de auxina.

Além disso, estacas herbáceas apicais apresentam um nível mais elevado de auxina endógena. Zuffellato-Ribas \& Rodrigues (2001) relatam que as estacas retiradas mais próximo do ápice do ramo, quando comparadas àquelas da base do ramo, possuem maior concentração endógena de auxina, pois estas substâncias se encontram principalmente

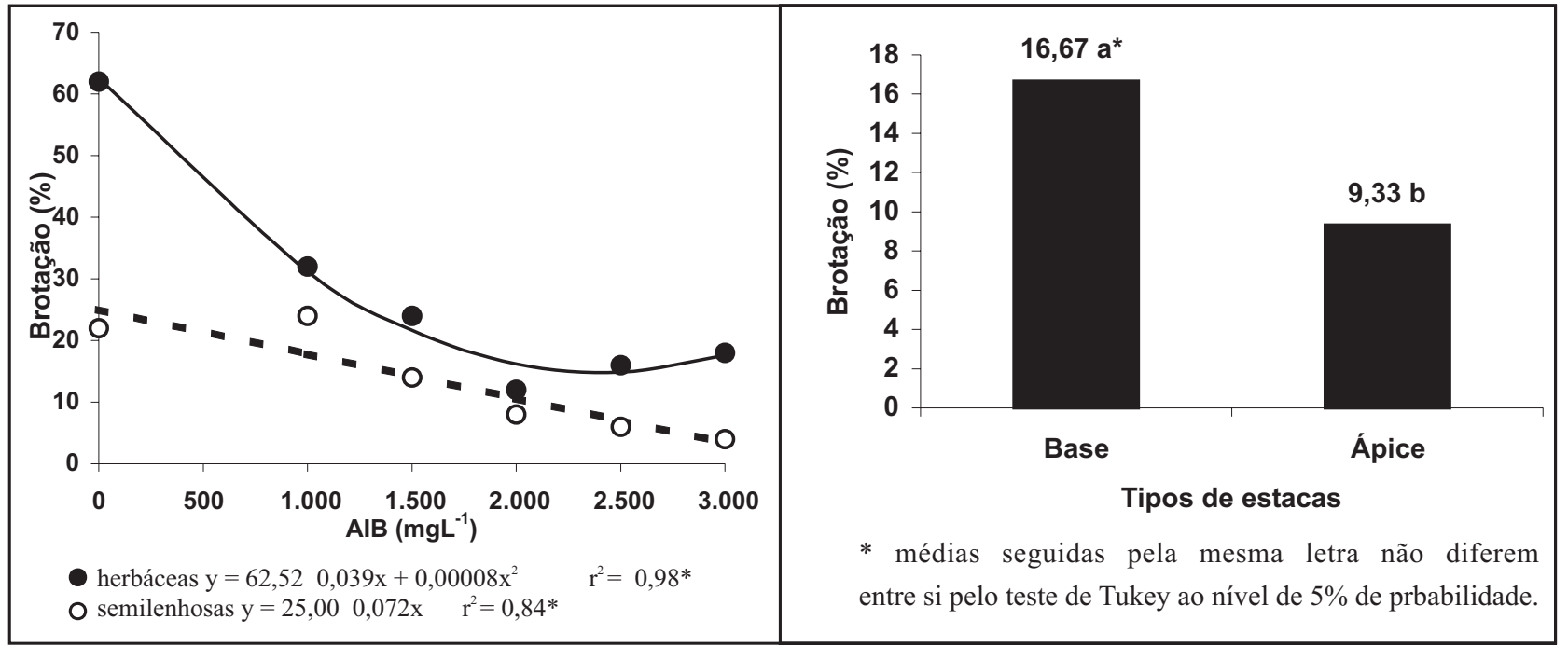

FIGURA 4 - Porcentagem de brotação de estacas herbáceas e semi-lenhosas tratadas com diferentes doses de AIB (A) e de estacas semi-lenhosas retiradas da base e do ápice dos ramos (B). 


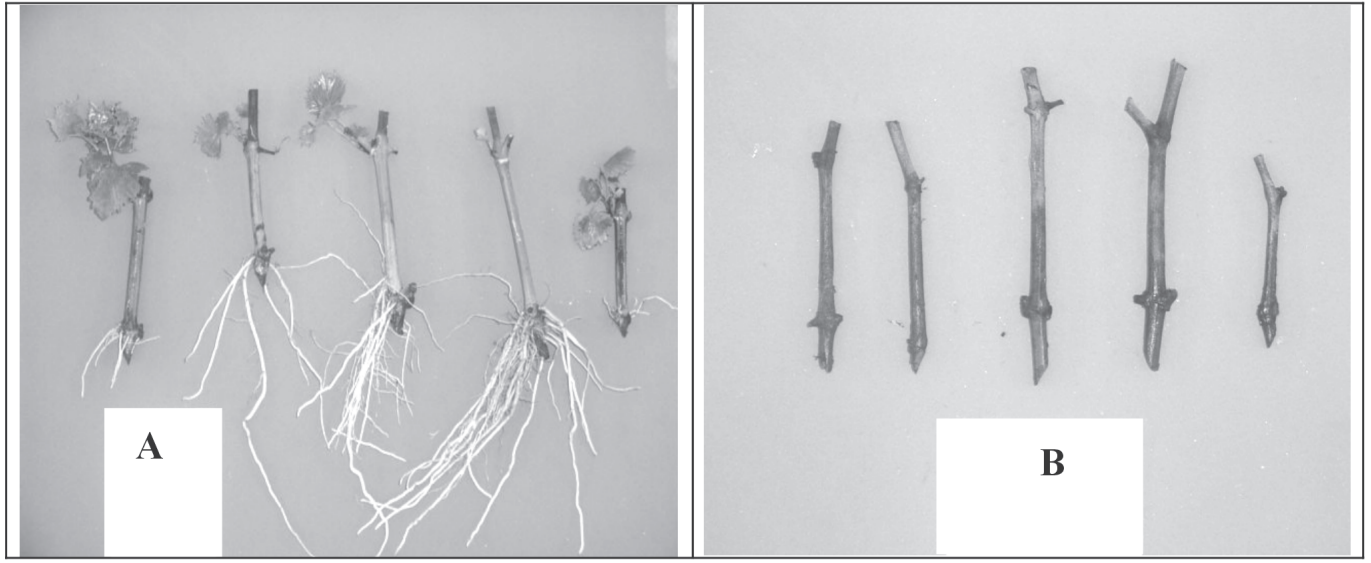

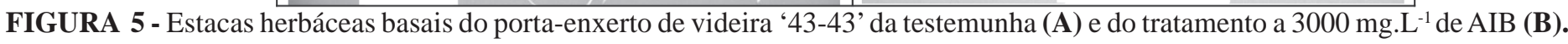

nos órgãos em crescimento ativo, tais como regiões meristemáticas, folhas jovens e sementes em desenvolvimento.

Apesar de as estacas semilenhosas terem apresentado uma correlação negativa entre porcentagem de enraizamento e doses de AIB, nota-se que este fitorregulador, na dose de $1.000 \mathrm{mgL}^{-1}$, apresentou valores superiores para esta variável (Figura 1); além disso, este tratamento proporcionou maior número e comprimento médio de raízes. De acordo com Zuffellato-Ribas \& Rodrigues (2001), a auxina sintética, dependendo da concentração e tempo de exposição, inibe ou estimula o crescimento e a diferenciação dos tecidos, existindo um nível ótimo para estas respostas fisiológicas, dependendo diretamente dos níveis endógenos dessas substâncias. Conclui-se, portanto, que as diferenças de comportamento observadas entre estacas herbáceas e semilenhosas, possivelmente, se devem aos distintos balanços hormonais de cada material vegetativo utilizado.

Desta forma, as estacas semilenhosas quando tratadas com AIB a $1.000 \mathrm{mgL}^{-1}$, provavelmente apresentavam um nível endógeno de auxina insatisfatório e foram beneficiadas pela aplicação do regulador vegetal. Além disso, conforme Alvarenga \& Carvalho (1983), a auxina endógena é relativamente solúvel, decompondo-se rapidamente nos tecidos vegetais. O AIB, por sua vez, é uma substância mais estável do que o AIA e, deste modo, mais efetiva na promoção do desenvolvimento de raízes, sendo que sua molécula passa rapidamente nos diferentes tecidos da planta onde os sistemas de enzimas oxidativas de auxinas a inativa de forma relativamente lenta.

A aplicação de AIB reduziu a porcentagem de brotação de estacas herbáceas e semi-lenhosas e, neste caso, acredita-se que a falta de raízes tenha inibido a brotação pela falta de nutrientes e água. Adicionalmente, as auxinas mobilizam nutrientes, podendo ter inibido a brotação quando aplicadas à base das estacas (Felippe, 1986).

As estacas semilenhosas apresentaram baixa porcentagem de brotação, provavelmente devido à entrada em dormência das gemas com o início do outono. A maior brotação das estacas basais, possivelmente, está relacionada ao menor desenvolvimento de raízes e, assim, à menor competição por reservas.

De maneira geral, as estacas herbáceas retiradas do ápice do ramo foram as mais adequadas para a propagação do porta-enxerto de videira ‘43-43’, propiciando maior porcentagem de enraizamento de brotação.

\section{CONCLUSÕES}

1.Estacas herbáceas e semilenhosas apresentaram alta porcentagem de enraizamento (66,0\% e 68,0\%, respectivamente) mesmo quando não tratadas com o regulador vegetal.

2.Estacas apicais provenientes de ramos herbáceos e semilenhosos apresentaram maior comprimento e massa de raízes quando comparadas às estacas basais.

3.Estacas semilenhosas tratadas com o AIB a $1.000 \mathrm{mgL}^{-1}$ apresentaram maior comprimento e massa de raízes.
4.A aplicação de AIB reduziu a porcentagem de enraizamento e de brotação de estacas herbáceas e semilenhosas.

\section{REFERÊNCIAS}

ALVARENGA, L. R.; CARVALHO,V.D. Uso de substâncias promotoras de enraizamento de estacas frutíferas. Informe Agropecuário, Belo Horizonte, v.9, n. 101, p. 45-55, 1983.

BASTOS, D.C. Efeito da época de coleta, estádio do ramo e do tratamento com IBA no enraizamento de estacas de caramboleira (Averhoa carambola L.). 2002. 75f. Dissertação (Mestrado em Agronomia) Faculdade de Ciências Agrárias e Veterinárias, Universidade Estadual Paulista, Jaboticabal, 2002.

BASTOS, D.C. ; MARTINS, A.B. ; SCALOPP, E.J. ; SARZI, I. ; FATINANSI, J.C. Pinfluencia do ácido indolbutírico no enraizamento de estacas apicais e basais de caramboleira (Averrhoa carambola L.) sob condições de nebulização intermitente. Revista Brasileira de Fruticultura, Jaboticabal, v.26, n.2, p.284-286, 2004.

BIASI, L.A. ; POMMER, C.V. ; PINO, P.A. Propagação de porta-enxertos de videira mediante estaquia semilenhosas. Bragantia, Campinas, v. 56, n. 2, p. 367-376, 1997.

FACHINELLO, J.C.; HOFFMANN, A.; NACHTIGAL, J.C.; KERSTEN, E.; FORTES, G.R.L. Propagação de plantas frutíferas de clima temperado. 2.ed. Pelotas: UFPel, 1995. 178p.

FELIPPE, G.M. Desenvolvimento. In: FERRI, M.G. (Coord.). Fisiologia vegetal 2. São Paulo: EPU, 1986. p.1-38.

JANICK, J. A ciência da horticultura. Rio de Janeiro: F. Bastos, 1966. 485p.

KRAMER, P.J.; KOZLOWSKI, T.T. Fisiologia das árvores. Lisboa: Fundação Calouste Gulbenkian, 1960. 745p.

ONO, E.O.; RODRIGUES, J.D. Aspectos da fisiologia do enraizamento de estacas caulinares. Jaboticabal: FUNEP, 1996. 83p.

PAPA, G. BOTTON, M. Pragas da videira. In: BOLIANI, A. C.; CORRÊA, L.S. Cultura de uva de mesa: do plantio à comercialização. Piracicaba: ALGRAF, 2001. p.201-220.

PIRES, E.J.P.; BIASI, L. A . Propagação da videira. In: POMMER, C.V. Uva: tecnologia de produção, pós-colheita, mercado. Porto Alegre: Cinco Continentes, 2003. p.295-350.

REDDY, V.V.P.; SINGH, R.; MURTHY, B.N.S. Rooting response of new grape hybrids to growth regulators application. Advances in Horticulture and Forestry, v.6, n.1, p.5-60, 1996.

SORIA, S.J.; CAMARGO, U.A.; FÂO, V.M.; BRAGHINI, L.C. Avaliação no campo da resistência de videiras americanas à pérola-da-terra Eurhizococcus brasiliensis, Brasil. In: CONGRESSO BRASILEIRO DE VITICULTURA E ENOLOGIA, 7., 1993. Bento Gonçalves. Anais... Bento Gonçalves, 1999. p.19-23.

ZUFFELLATO-RIBAS, K.C.; RODRIGUES, J.D. Estaquia: uma abordagem dos principais aspectos fisiologicos. Curitiba: UFPR, 2001.39p. 